\title{
Article
}

\section{Estimation of the Periodontal Inflamed Surface Area by Simple Oral Examination}

\author{
Yoshiaki Nomura ${ }^{1}$ (D), Toshiya Morozumi ${ }^{2, *}$ (D), Yukihiro Numabe ${ }^{3}$, Yorimasa Ogata ${ }^{4}$, Yohei Nakayama ${ }^{4}$, \\ Tsutomu Sugaya ${ }^{5}$, Toshiaki Nakamura ${ }^{6}{ }^{D}$, Soh Sato ${ }^{7}$, Shogo Takashiba ${ }^{8}$, Satoshi Sekino ${ }^{3}$, Nobuo Yoshinari ${ }^{9}{ }^{(D)}$, \\ Nobuhiro Hanada ${ }^{1}$ (D), Naoyuki Sugano ${ }^{10}$, Mitsuo Fukuda ${ }^{11}$, Masato Minabe ${ }^{2}$, Makoto Umeda ${ }^{12}$, Koichi Tabeta ${ }^{13}$, \\ Keiso Takahashi ${ }^{14}$, Kazuyuki Noguchi ${ }^{6}$, Hiroaki Kobayashi ${ }^{15}$, Hideki Takai ${ }^{4}$, Fusanori Nishimura ${ }^{16}$, \\ Fumihiko Suzuki ${ }^{17}$ (D) Erika Kakuta ${ }^{18}$, Atsutoshi Yoshimura ${ }^{19}$, Atsushi Saito ${ }^{20}$ and Taneaki Nakagawa ${ }^{21}$
}

1 Department of Translational Research, Tsurumi University School of Dental Medicine, Yokohama 230-8501, Japan; nomura-y@tsurumi-u.ac.jp (Y.N.); hanada-n@tsurumi-u.ac.jp (N.H.)

2 Division of Periodontology, Department of Oral Interdisciplinary Medicine, Graduate School of Dentistry, Kanagawa Dental University, Yokosuka 238-8580, Japan; minabe@kdu.ac.jp

3 Department of Periodontology, School of Life Dentistry at Tokyo, The Nippon Dental University, Tokyo 102-8159, Japan; numabe-y@tky.ndu.ac.jp (Y.N.); sekino-s@tky.ndu.ac.jp (S.S.)

4 Department of Periodontology, Nihon University School of Dentistry at Matsudo, Matsudo 271-8587, Japan; nakayama.youhei@nihon-u.ac.jp (Y.N.); ogata.yorimasa@nihon-u.ac.jp (Y.O.); takai.hideki@nihon-u.ac.jp (H.T.)

5 Division of Periodontology and Endodontology, Department of Oral Health Science, Hokkaido University Graduate School of Dental Medicine, Sapporo 060-8586, Japan; sugaya@den.hokudai.ac.jp

6 Department of Periodontology, Kagoshima University Graduate School of Medical and Dental Sciences, Kagoshima 890-8544, Japan; toshi-n@dent.kagoshima-u.ac.jp (T.N.); kazuperi@dent.kagoshima-u.ac.jp (K.N.)

check for updates

Citation: Nomura, Y.; Morozumi, T.; Numabe, Y.; Ogata, Y.; Nakayama, Y.; Sugaya, T.; Nakamura, T.; Sato, S.; Takashiba, S.; Sekino, S.; et al. Estimation of the Periodontal Inflamed Surface Area by Simple Oral Examination. J. Clin. Med. 2021, 10, 723. https://doi.org/10.3390/ jcm10040723

Academic Editor: Camile S. Farah Received: 5 January 2021

Accepted: 8 February 2021

Published: 12 February 2021

Publisher's Note: MDPI stays neutral with regard to jurisdictional claims in published maps and institutional affiliations.

Copyright: (c) 2021 by the authors. Licensee MDPI, Basel, Switzerland. This article is an open access article distributed under the terms and conditions of the Creative Commons Attribution (CC BY) license (https:/ / creativecommons.org/licenses/by/ $4.0 /$ )
7 Department of Periodontology, School of Life Dentistry at Niigata, The Nippon Dental University, Niigata 951-8580, Japan; s-sato@ngt.ndu.ac.jp

8 Department of Pathophysiology-Periodontal Science, Okayama University Graduate School of Medicine, Dentistry and Pharmaceutical Sciences, Okayama 700-8525, Japan; stakashi@okayama-u.ac.jp

9 Department of Periodontology, School of Dentistry, Matsumoto Dental University, Shiojiri 399-0781, Japan; nobuo.yoshinari@mdu.ac.jp

10 Department of Periodontology, Nihon University School of Dentistry, Tokyo 101-8310, Japan; sugano.naoyuki@nihon-u.ac.jp

11 Department of Periodontology, School of Dentistry, Aichi Gakuin University, Nagoya 464-8650, Japan; fukuda-m@dpc.agu.ac.jp

12 Department of Periodontology, Osaka Dental University, Hirakata 573-1121, Japan; umeda-m@cc.osaka-dent.ac.jp

13 Division of Periodontology, Department of Oral Biological Science, Niigata University Graduate School of Medical and Dental Sciences, Niigata 951-8514, Japan; koichi@dent.niigata-u.ac.jp

14 Division of Periodontics, Department of Conservative Dentistry, Ohu University School of Dentistry, Koriyama 963-8611, Japan; ke-takahashi@den.ohu-u.ac.jp

15 Department of Periodontology, Graduate School of Medical and Dental Sciences, Tokyo Medical and Dental University, Tokyo 113-8510, Japan; h-kobayashi.peri@tmd.ac.jp

16 Section of Periodontology, Division of Oral Rehabilitation, Faculty of Dental Science, Kyushu University, Fukuoka 812-8582, Japan; fusanori@dent.kyushu-u.ac.jp

17 Division of Dental Anesthesiology, Department of Oral Surgery, Ohu University School of Dentistry, Koriyama 963-8611, Japan; f-suzuki@den.ohu-u.ac.jp

18 Department of Oral Microbiology, Tsurumi University School of Dental Medicine, Yokohama 230-8501, Japan; kakuta-erika@tsurumi-u.ac.jp

19 Department of Periodontology and Endodontology, Nagasaki University Graduate School of Biomedical Sciences, Nagasaki 852-8588, Japan; ayoshi@nagasaki-u.ac.jp

20 Department of Periodontology, Tokyo Dental College, Tokyo 101-0061, Japan; atsaito@tdc.ac.jp

21 Department of Dentistry and Oral Surgery, School of Medicine, Keio University, Tokyo 160-8582, Japan; tane@z6.keio.jp

* Correspondence: morozumi@kdu.ac.jp; Tel.: +81-46-822-8855

Abstract: The periodontal inflamed surface area (PISA) is a useful index for clinical and epidemiological assessments, since it can represent the inflammation status of patients in one contentious variable. However, calculation of the PISA is difficult, requiring six point probing depth measurements with or without bleeding on probing on 28 teeth, followed by data input in a calculation program. More 
simple methods are essential for screening periodontal disease or in epidemiological studies. In this study, we tried to establish a convenient partial examination method to estimate PISA. Cross-sectional data of 254 subjects who completed active periodontal therapy were analyzed. Teeth that represent the PISA value were selected by an item response theory approach. The maxillary second molar, first premolar, and lateral incisor and the mandibular second molar and lateral incisor were selected. The sum of the PISAs of these teeth was significantly correlated with the patient's PISA $\left(R^{2}=0.938\right)$. More simply, the sum of the maximum values of probing pocket depth with bleeding for these teeth were also significantly correlated with the patient's PISA $\left(R^{2}=0.6457\right)$. The simple model presented in this study may be useful to estimate PISA.

Keywords: periodontal diseases; periodontal pocket; health status indicators; periodontal inflamed surface area (PISA); item response theory

\section{Introduction}

Several periodontal indexes have been proposed and used for clinical or epidemiological assessments. The indexes used in epidemiological studies include the commonality periodontal index (CPI) [1-3], clinical attachment level (CAL) [4,5], and bleeding on probing (BOP) [6], while other studies used combinations of indexes, such as CPI, CAL, BOP, and probing pocket depth (PD) [7], CAL, $\mathrm{PD}$, gingival index (GI), and plaque index (PII) [8], CAL, PD, and GI [9], and CAL and BOP [10]. For clinical assessments, PD, CAL, and BOP have been commonly used for evaluation of diagnoses or therapeutic effects. Although summary statistics of these parameters, like the mean or maximum value, have been conventionally used, these summary statistics involve loss of information. The periodontal inflamed surface area (PISA) was developed to address these issues [11]. PISA is a very convenient index that reflects the surface area of bleeding pocket epithelium in square millimeters and is calculated using conventional clinical parameters of periodontal health, namely BOP combined with either PD, or CAL and gingival recession [11]. Thus, PISA can represent the inflammation status of subjects in one contentious variable, for which calculation of mean or maximum value is not necessary. Recent study have reported that PISA is effectively associated with systemic markers of low-grade inflammation, such as C-reactive protein [12]. Periodontal disease is a risk factor for non-communicable diseases through the localized inflammation and periodontal pathogens [13-20]. Therefore, PISA may be an optimal index to investigate the correlation between periodontal disease and non-communicable diseases.

However, calculation of PISA is an extremely difficult task, requiring six probing depth measurements of all the teeth and BOP and PD data for 168 sites. A simpler method is indispensable for screening or epidemiological studies. Therefore, in this study, we tried to establish a convenient partial examination method to estimate PISA. Our simple, convenient, and evidence-based partial oral examination method to estimate PISA may be a useful tool like other periodontal indexes for screening or epidemiological studies.

\section{Materials and Methods}

\subsection{Study Design}

\subsubsection{Setting}

This study was a part of a clinical research project conducted by the Japanese Society of Periodontology in cooperation with 17 facilities (one clinic and 16 university hospitals) in Japan for the diagnosis of periodontitis. In our previous reports, we had analyzed 124 participants who successfully completed the study protocol [21-23]. For this study, we selected 254 patients with chronic periodontitis who had completed their active treatment under the regulations of the Japanese health insurance system. After registering for a screening examination before their follow-up, all 254 patients were analyzed in the study. 
The inclusion criteria were age greater than 30 years, number of remaining teeth more than 20, and systemically healthy status.

\subsubsection{Diagnosis}

Each patient was diagnosed according to the guidelines used at the time (Guidelines of the American Academy of Periodontology) [24]. Oral examinations were carried out by one examiner at each institute (T.M., Y.N., T.S., T.N., S.S., S.S., N.Y., N.S., M.F., M.M., K.N., H.K., H.T., F.S., A.Y., and T.N.). Each examiner was a periodontist licensed by the Japanese Society of Periodontology. Intra- and interexaminer calibration sessions were conducted using periodontal disease models (P15FE-500HPRO-S2A1-GSF, NISSIN, Kyoto, Japan) at the beginning and middle of the study period. In brief, full-mouth PD and recessions were measured twice, and repeatability for CAL was assessed. The examiner was judged to have made reproducible measurements after reaching a percentage of agreement within $\pm 1 \mathrm{~mm}$ between repeated measurements of at least $95 \%$ of measurements.

\subsection{Research Data}

In this study, we analyzed PD and BOP data for calculation of PISA. A freely downloadable spreadsheet is available to calculate the PISA [11], and CAL and PII were used as associated factors for PISA. Details of the data are described in our previous reports [21-23].

\subsection{Statistical Analysis}

The number of bleeding sites and PDs were measured at six sites for all of the remaining teeth with a periodontal probe (CP-12 Color-Coded Probe; Hu-Friedy, Chicago, IL, USA). To find out the optimal value for IRT analysis, 6 kinds of cut-off points were set for number of bleeding site per teeth: $(0,1-6),(0$ and $1,2-6),(0-2,3-6),(0-3,4-6),(0-4,5$ and $6)$, and $(0-5,6)$. For each cut-off point, models were constructed. For the PD, the maximum value $(\mathrm{mm})$ for one tooth in the six sites were used.

By using the dichotomized data, a three-parameter logistic model based on the item response theory (IRT) was applied. For the IRT analysis, R software with the ltm and irtoys package was used.

\subsection{Ethical Approval}

The study was conducted in compliance with the principles outlined in the Helsinki Declaration. Written informed consent was obtained from each participant, and the protocol was approved by the Institutional Review Board of each participating institution. The ethics committee members' names and reference numbers are as follows: The regional ethical committee of the Faculty of Dentistry, Niigata University (20-R17-08-06); Keio University School of Medicine, Ethics Committee (20080096); Ethical Committee of Kagoshima University Medical and Dental Hospital (20-58); The Ethics Committee, Nagasaki University Graduate School of Biomedical Sciences (0846-2); Ethical Committee of Kyushu University Faculty of Dental Science (20-11); The Ethics Committee of Osaka Dental University (80712); Ethics Committee of Aichi Gakuin University, School of Dentistry (158); The Ethics Committee of Matsumoto Dental University (0090); The Institutional Review Board of Nippon Dental University (2-1-22); Ethical Committee of Nihon University School of Dentistry (EP08D016); Dental Research Ethics Committee of Tokyo Medical and Dental University (660); Ethics Committee in Nihon University School of Dentistry at Matsudo (EC 08-014); Ethics Committee of Tokyo Dental College (208); The Ethical Review Committee of The Nippon Dental University School of Life Dentistry at Niigata (151); Ohu University Research Ethics Committee (52); Institutional Review Board for Clinical Research of Hokkaido University Hospital (008-0113). 


\section{Results}

\subsection{Participant Characteristics}

The study population consisted of 114 men and 140 women. Their mean age was $55.6+/-10.3$ years, and their mean number of remaining teeth was $25.4+/-2.61$.

\subsection{Prediction of PISA by IRT Analysis Based on the Number of BOP Sites}

Since PISA is calculated on the basis of BOP and PD measurements, to reduce the number of BOP measurements, IRT analysis was performed. Cut-off points were set as at least 1, 2, 3, and 4 sites for BOP. The ability, which indicates the weighted sum of the total number of bleeding sites, was calculated for each participant. Scatter plots were obtained for the PISA against the ability calculated by IRT analysis. After $\log _{10}$ transformation of PISA, linear relationships were observed. The results are shown in Figure 1, and the models are shown in Table S1. Item response curves and item information curves are shown in Figure S1.

(A)

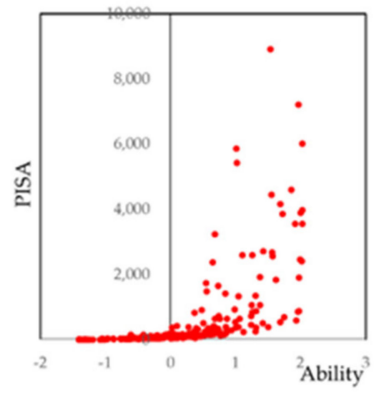

(C)

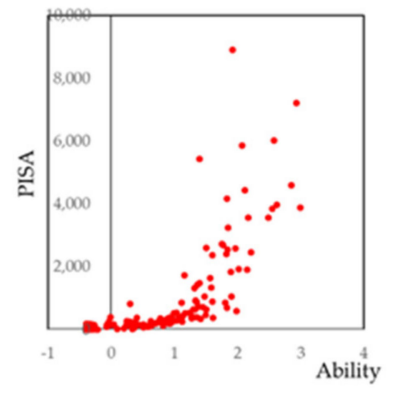

(B)
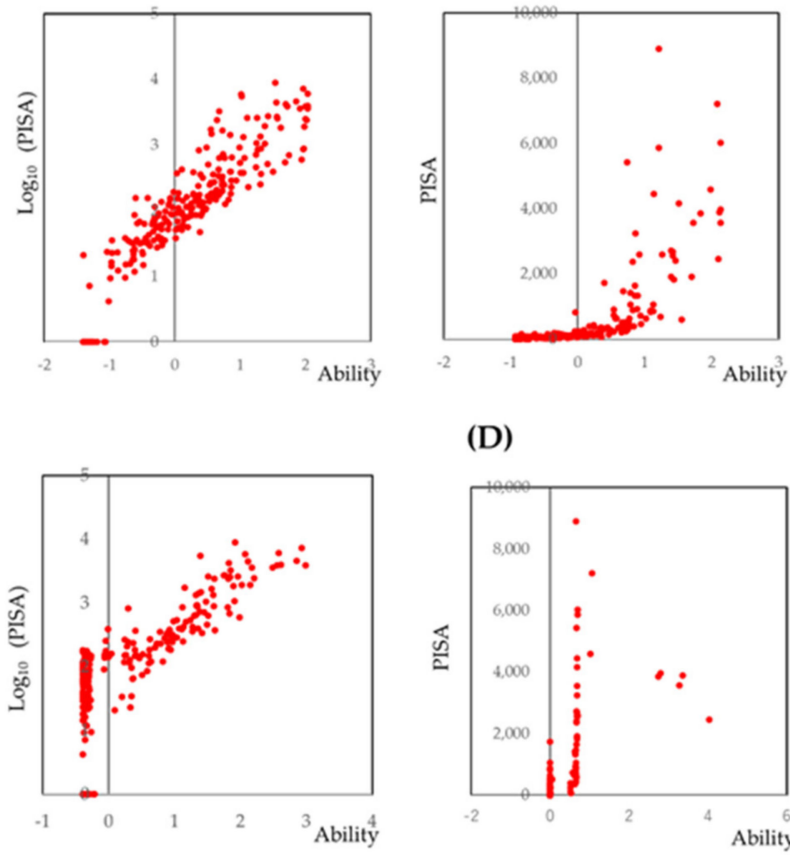

(D)
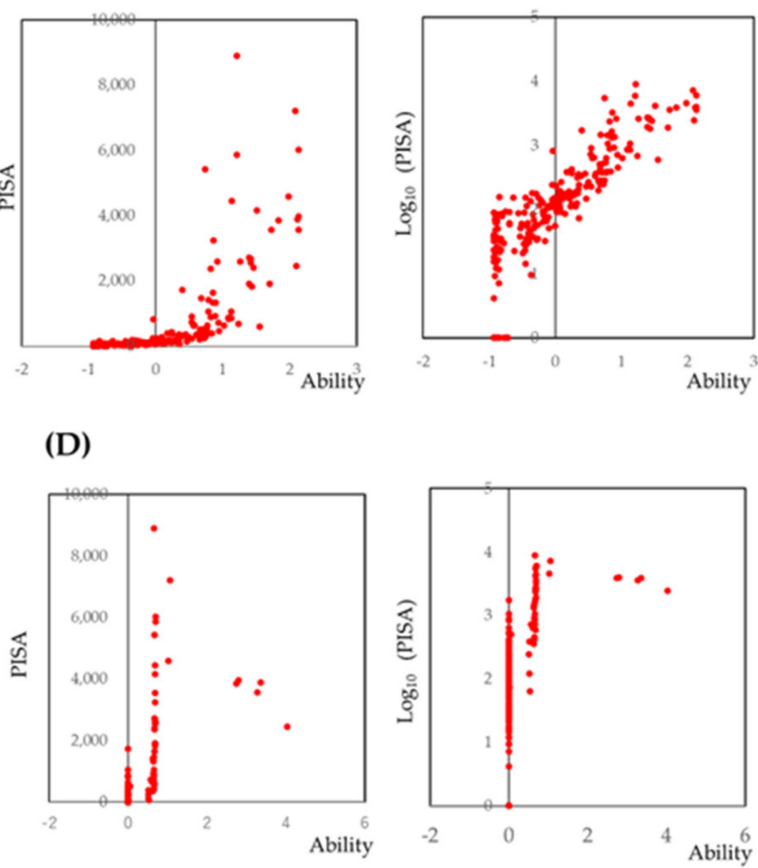

Figure 1. Scatter plots of PISA against the number of bleeding sites within each tooth. (A-D) Scheme 1. 2, 3, and 4 bleeding sites within each tooth. Ability, which indicates the weighted sum of the number of sites with bleeding on probing, was calculated by the three-parameter logistic model based on item response theory analysis. When PISA was $\log _{10}$ transformed, linear relationships were observed.

The results indicated that at least one site with bleeding for each tooth may be enough for evaluation of bleeding on probing.

\subsection{Prediction of PISA by the Maximum Value of the PD at Each Tooth by IRT Analysis}

In clinical settings, even the calculation of mean values of PD may be laborious. Thus, assessments based on the maximum value are simpler and more suitable for rapid evaluations. Therefore, the maximum PD value for each tooth was used as the variable. To investigate which site represents the PISA, a three-parameter logistic model based on IRT was used. To transform the maximum values for dichotomous variable, cut-off values were set as $>3 \mathrm{~mm},>4 \mathrm{~mm}, 5 \mathrm{~mm}$, and $6 \mathrm{~mm}$. The results are shown in Figure 2, the models are indicated in Table S2, and the item response curves and item information curves are shown in Figure S2. 
(A)

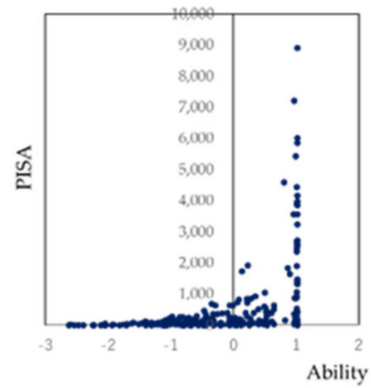

(C)

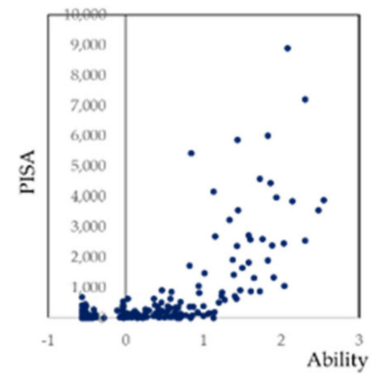

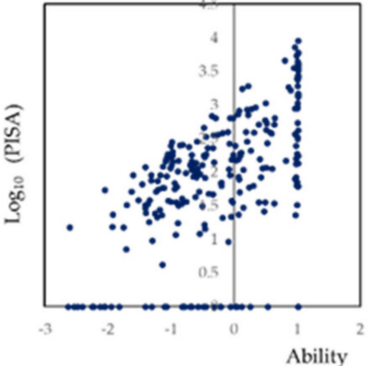

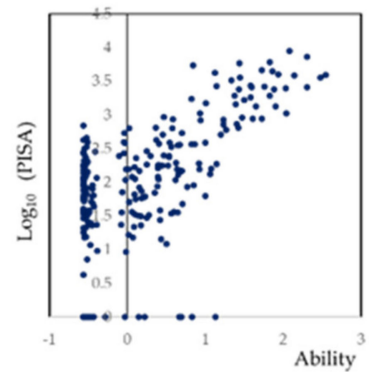

(B)
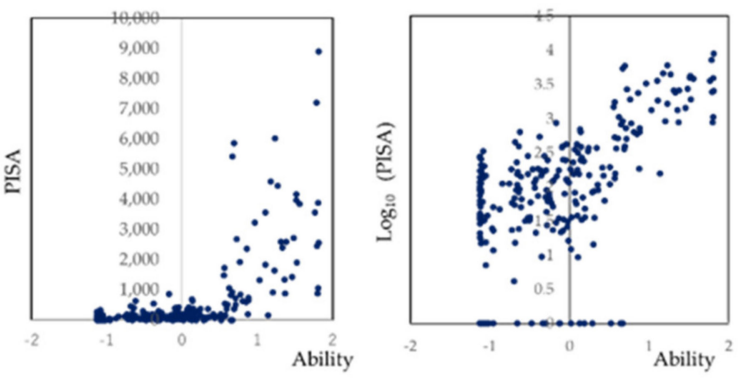

(D)

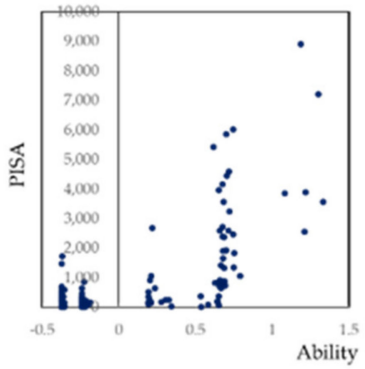

Figure 2. Scatter plots of PISA against the maximum value of PD within each teeth. (A-D) shows the findings with cut-off points of 3, 4, 5, and $6 \mathrm{~mm}$ of PD within one tooth. When PISA was $\log _{10}$ transformed, linear relationships were observed.

\subsection{Prediction of PISA Based on the Selected Sites}

The item information curves in Figure S1 and S2 provided valuable information for tooth selection. The area under the information curves for each tooth were calculated, and the results were presented by the mean values for left and right teeth (Table 1). Teeth with relatively higher information were the maxillary second molar, maxillary first premolar, maxillary lateral incisor, mandibular second molar, and mandibular lateral incisors. To confirm that the selected teeth were optimal, scatterplots of the overall PISA against the PISAs of these teeth were illustrated. The results are presented in Figure S3. $R^{2}$ values of these teeth were relatively higher.

Table 1. Item information for tooth type for the number of bleeding sites and the maximum value of probing depth.

\begin{tabular}{|c|c|c|c|c|c|c|c|}
\hline & & \multicolumn{3}{|c|}{ Bleeding on Probing } & \multicolumn{3}{|c|}{ Maximum Value of Probing Depth } \\
\hline & & 1 Site & 2 Sites & 3 Sites & $3 \mathrm{Mm}$ & $4 \mathrm{~mm}$ & $5 \mathrm{~mm}$ \\
\hline \multirow{7}{*}{ Maxillary } & 2nd Molar & 27.0 & 35.9 & 128.7 & 22.4 & 29.9 & 32.1 \\
\hline & 1st Molar & 25.4 & 23.3 & 35.9 & 24.0 & 35.9 & 43.8 \\
\hline & 2nd Premolar & 30.7 & 32.3 & 47.0 & 35.1 & 41.0 & 47.8 \\
\hline & 1st Premolar & 33.7 & 39.9 & 53.8 & 30.5 & 40.1 & 43.7 \\
\hline & Canine & 28.5 & 35.1 & 48.0 & 32.2 & 43.5 & 429.5 \\
\hline & $\begin{array}{l}\text { Lateral } \\
\text { incisor }\end{array}$ & 27.8 & 48.4 & 71.7 & 30.8 & 44.8 & 49.8 \\
\hline & $\begin{array}{l}\text { Central } \\
\text { incisor }\end{array}$ & 30.7 & 32.1 & 42.4 & 28.7 & 38.5 & 41.4 \\
\hline \multirow{7}{*}{ Mandibular } & 2nd Molar & 28.0 & 27.3 & 36.6 & 24.6 & 34.5 & 30.5 \\
\hline & 1st Molar & 27.8 & 27.6 & 39.1 & 15.0 & 37.7 & 47.6 \\
\hline & 2nd Premolar & 26.7 & 27.2 & 32.8 & 32.3 & 34.6 & 31.7 \\
\hline & 1st Premolar & 32.6 & 27.9 & 33.6 & 31.1 & 43.9 & 39.0 \\
\hline & Canine & 24.8 & 30.3 & 35.1 & 35.3 & 47.7 & 51.6 \\
\hline & $\begin{array}{l}\text { Lateral } \\
\text { incisor }\end{array}$ & 32.0 & 32.6 & 32.6 & 43.1 & 48.3 & 41.3 \\
\hline & $\begin{array}{l}\text { Central } \\
\text { incisor }\end{array}$ & 36.8 & 32.7 & 34.8 & 42.8 & 46.2 & 35.5 \\
\hline
\end{tabular}




\subsection{Prediction of PISA Based on the Selected Teeth}

\subsubsection{Correlation of PISA of Selected Teeth with PISA}

On the basis of the data presented in Table 1 and Figure S2, five teeth were selected: the maxillary second molar, maxillary first molar, maxillary lateral incisor, mandibular second molar, and mandibular lateral incisor. The scatter plot for the PISA against the sum of PISAs of these 10 teeth are provided in Figure 3. Since linear regression is affected by outliers, PISA less than 1000 is illustrated again in Figure 3B. The $\mathrm{R}^{2}$ was 0.938 for all the data and 0.817 for PISA less than 1000 .

(A)

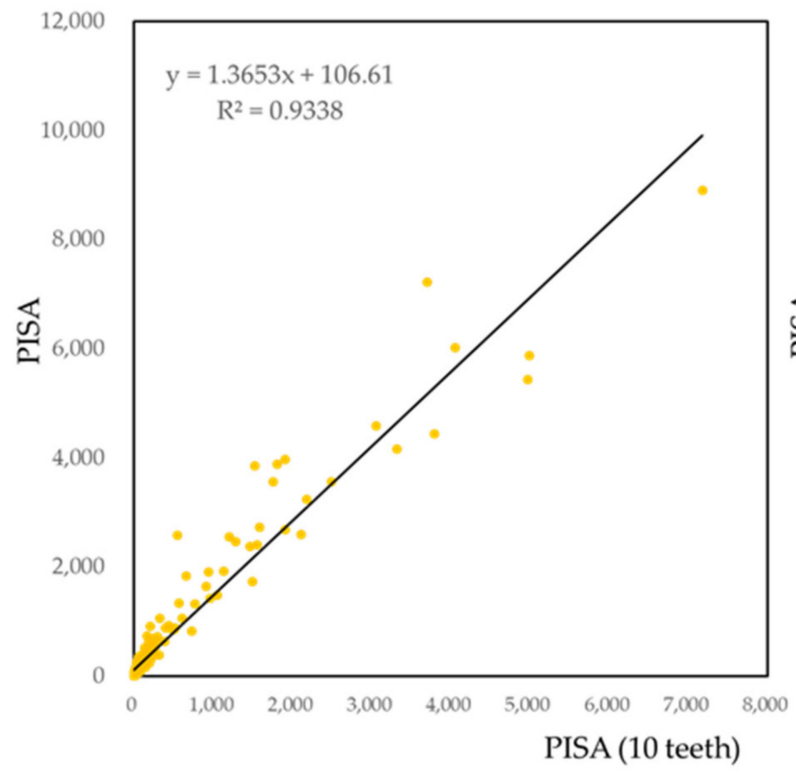

(B)

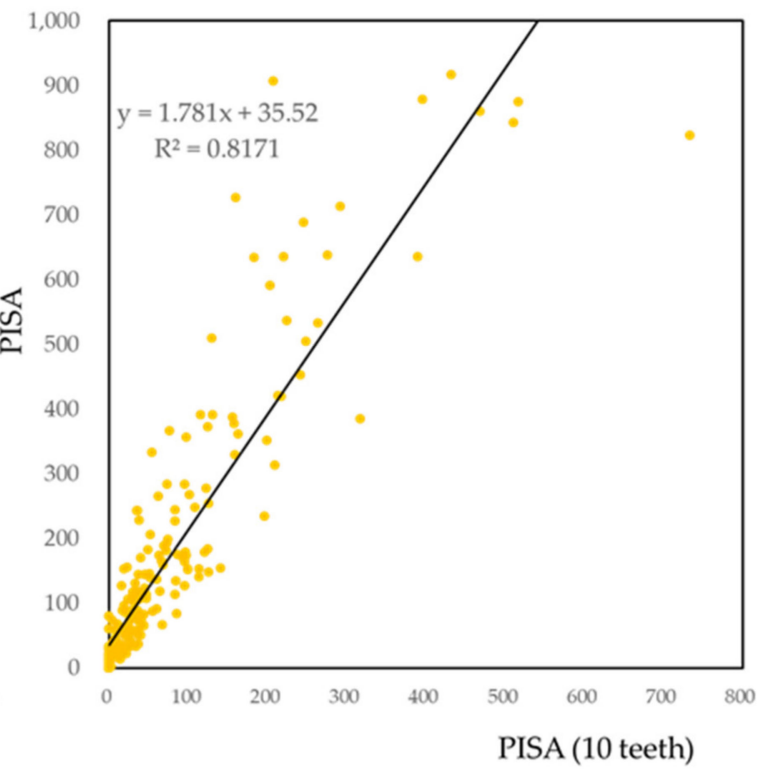

Figure 3. Scatter plot of PISA against the maximum value of PD in each tooth. (A,B) are the same figure. (B) is magnified PISA for less than 1000. Regression line (B) was calculated by PISA less than 1000.

\subsubsection{Prediction of PISA by the Maximum Value of PD}

To create a simple model for clinical convenience, the sum of the maximum PD values with BOP were used to generate a summary score to predict PISA. The scatter plot with the net values showed an exponential curve (Figure $4 \mathrm{~A}$ ). When the values were $\log _{10}$ transformed, a linear relationship was observed. The PISA against a value of 0 on the $X$-axis was less than 2 . This indicated that when the 10 teeth did not show any bleeding, PISA is less than 100.

The effect of missing teeth is uncertain. In addition, a selected site of 0 may not guarantee a PISA value of 0 . Figure 4 was categorized by the groups; Group 0: no missing teeth and no bleeding in 10 teeth, Group 1: one missing teeth and no bleeding in nine teeth, Group 2: two missing teeth and no bleeding in eight teeth, Group 3: three missing teeth and no bleeding in seven teeth, Group 10: one missing teeth in 10 teeth, Group 11: one missing teeth in 10 teeth, Group 12: two missing teeth in 10 teeth, Group 13: three missing teeth in ten teeth, Group 14: four or five missing teeth in ten teeth (Figure S4). 
(A)

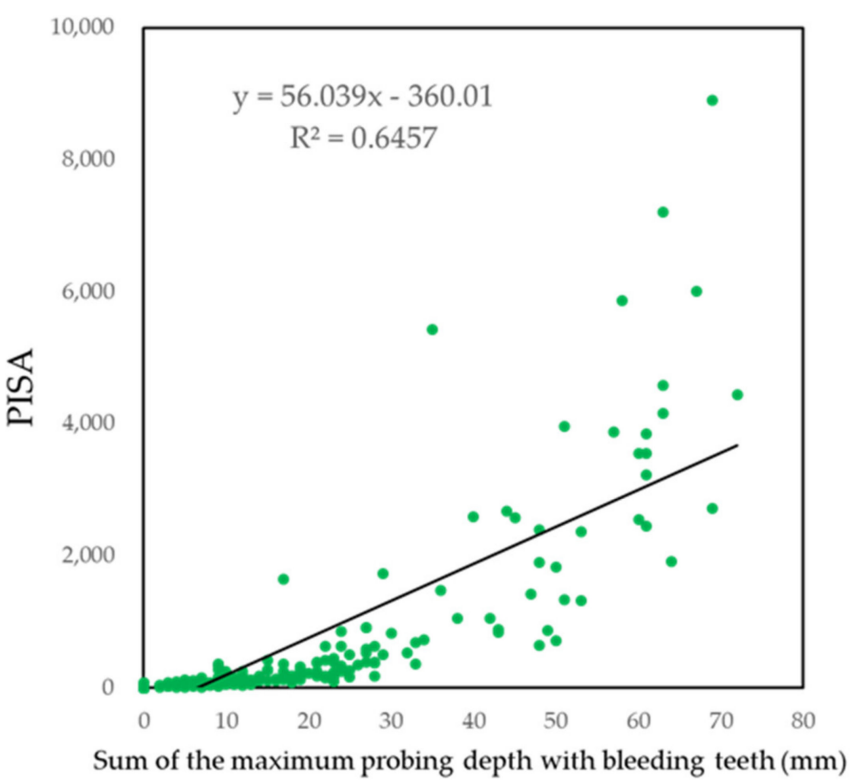

(B)

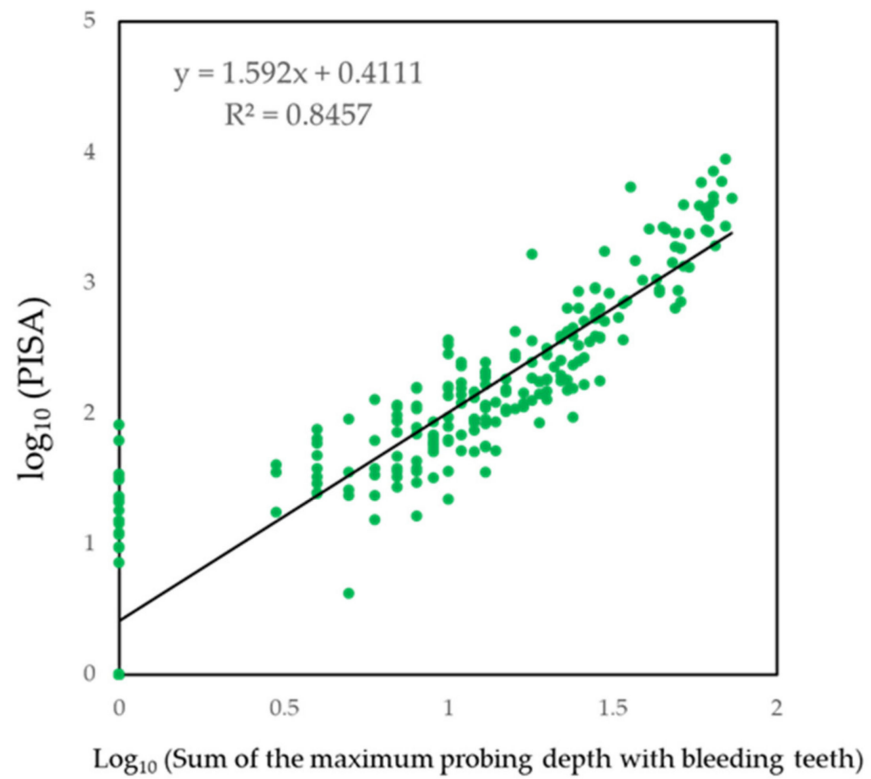

Figure 4. Scatter plot of PISA against sum of the maximum values of PD for each of the bleeding teeth. (A) shows the scatter plot by net values. (B) shows the values were $\log _{10}$ transformed.

If there was no bleeding in ten teeth, PISA was estimated a less than 100 . Thus, there may be little effect of missing teeth on PISA (Figure 4B).

The final model is presented in the following formula:

$$
\begin{gathered}
\log _{10}(\text { PISA })=1.592 \times \log _{10} \sum(\text { maximum value of probing depth with } \\
\text { bleeding of selected teeth })+0.4111
\end{gathered}
$$

Selected teeth are maxillary second molar, maxillary first premolar, maxillary lateral incisor, mandibular second molar, and mandibular lateral incisor.

When separately predicted PISA by bleeding of approximal surface and flat surface, effects of bleeding in approximal surface was larger than flat surface. The results are shown in Figure S5.

Additionally, for clinical convenience, quick reference for the predictive values of PISA calculated by the formula described above is presented in Table S3.

\section{Discussion}

In this study, we tried to establish a partial examination method using the selected teeth to estimate PISA. The final simple model that uses the sum of the maximum PD values of the 10 selected teeth with BOP may be useful to estimate PISA.

Many studies have used PISA for evaluation of periodontal conditions. Since PISA reflects the inflammation status of periodontal tissue, these studies focused on the correlation of PISA and systemic diseases [25-43], or the correlation of PISA with novel disease markers [41-48]. In the present study, IRT analysis was used to set a cut-off point for the number of bleeding sites and the maximum values of PD in a single tooth. IRT is based on the relationship between the performance of the subjects on a test item and the overall measured ability. It can calculate the weight of each item and the ability of individuals. These values correspond to the weight of clinical symptoms of each teeth and PISA. Therefore, selection of the teeth as items and calculation of the ability as PISA with IRT is a reasonable approach.

As shown in Figure 1, the cut-off point of one site of bleeding in one tooth may be suitable. When the cut-off point was set to more than two sites, the number of participants 
with an estimated PISA of 0 increased. The number of participants who missed with less than 100 PISA was also increased. If the PD is transformed to a dichotomous variable by an optimal cut-off point, several statistical methods for the screening such as ROC analysis and evaluations of sensitivity, specificity, positive predictive value, and negative predictive value become available. However, the optimal cut-off points were not presented by previous studies. In addition, the scatterplots shown in Figure 2 were not as clear as the scatter plot shown in Figure 1A. Therefore, in the model shown in Figure 4, a simple sum of the maximum value of PD in the selected teeth with BOP was applied as an independent value. However, this simple model was sufficient to estimate PISA. Missing teeth had little effect on PISA in the simple model shown in Figure 4. Since PISA is a sum of the PISAs of each tooth, a value of 0 as a result of missing teeth would not include the PISA. However, the simple model could not detect participants with PISA less than 100.

The PISA value for the diagnosis of periodontal disease has been defined previously [48]. However, calculation of PISA is more laborious than examination of periodontal tissue for the diagnosis. The value of PISA was correlated with the clinical parameters of periodontal tissue and periodontal pathogens [49] and dental plaque metabolic byproducts [50]. Only a few studies have investigated the characteristics of PISA. Thus, additional studies are necessary to understand the characteristics of PISA.

Representative six teeth by Ramfjord was used in epidemiological studies. Although it reflect the entire periodontal disease, those sites were selected from studies by numerous investigators using (a) P.M.A. index, (b) formation of pocket depth and bone loss, and (c) teeth extraction record [51]. While PISA focus on degree of periodontal inflammation, as an advantage of the study, we calculated using our raw data for selection.

There is a limitation of this study. Study population of this study was consisted of the patients who finished periodontal treatment. There may be bias in periodontal conditions. Further study is necessary to confirm the availability the model presented in this study by epidemiological study which included the periodontal healthy subjects and subjects with severe periodontal conditions. In addition, further study is necessary to confirm application of the model presented in this study for the patients with systemic diseases.

In this study, by using patients' data, we tried to establish a convenient partial examination method to estimate PISA. Simple, convenient, and evidence-based partial examination methods to estimate PISA may be useful tools for the screening or epidemiological studies, such as other periodontal indexes.

Supplementary Materials: The following are available online at https://www.mdpi.com/2077-0 383/10/4/723/s1, Figure S1: Item response curves and item information curves of the number of bleeding sites, Figure S2: Item response curves and item information curves of the maximum value of probing depth, Figure S3. Scatter plot of PISA against the PISA of each tooth type, Figure S4: Scatter plot of PISA against the PISA of each tooth type. Figure S5: Scatter plot of PISA against the PISA calculated by bleeding with approximal surface and flat surface. Table S1: Three-parameter logistic model for the number of bleeding sites, Table S2: Three-parameter logistic model for the maximum value of probing depth. Table S3: Quick reference of the predictive PISA values.

Author Contributions: Conceptualization, Y.N. (Yoshiaki Nomura) and T.M.; methodology, Y.N. (Yoshiaki Nomura); software, Y.N. (Yoshiaki Nomura); validation, E.K. and N.H.; formal analysis, Y.N. (Yoshiaki Nomura); investigation, T.M., Y.N. (Yukihiro Numabe), Y.O., Y.N. (Yohei Nakayama), T.S., T.N. (Toshiaki Nakamura), S.S. (Soh Sato), S.S. (Satoshi Sekino), N.Y., N.S., M.F., M.M., M.U., K.T., K.N., H.K., H.T., F.N., F.S., A.Y., A.S., and T.N. (Taneaki Nakagawa); data curation, S.T.; writing-original draft preparation, Y.N. (Yoshiaki Nomura); writing-review and editing, Y.N. (Yoshiaki Nomura), T.M. and K.T.; visualization, Y.N. (Yoshiaki Nomura); supervision, T.M.; project administration, T.M. and T.N.; funding acquisition, T.N. All authors have read and agreed to the published version of the manuscript.

Funding: This research was funded by a clinical research project grant from the Japanese Society of Periodontology for the diagnosis of periodontitis.

Informed Consent Statement: Informed consent was obtained from all subjects involved in the study. 
Data Availability Statement: The data presented in this study are available on request from the corresponding author. The data are not publicly available due to privacy.

Acknowledgments: The authors thank Hiromasa Yoshie, Toshihide Noguchi, Masamitsu Kawanami, Koichi Ito, Yuichi Izumi, Yoshitaka Hara, Osamu Fujise, Yuzo Abe, Tomoo Kono, Asako Makino-Oi, and Chie Fukaya, for their advice and useful comments.

Conflicts of Interest: The authors declare no conflict of interest.

\section{References}

1. Thomas, J.T.; Thomas, T.; Ahmed, M.; Kannan, S.K.; Abdullah, Z.; Alghamdi, S.A.; Joseph, B. Prevalence of Periodontal Disease among Obese Young Adult Population in Saudi Arabia-A Cross-Sectional Study. Medicina 2020, 56, 197. [CrossRef]

2. Lee, K.; Kim, J. Dairy Food Consumption is Inversely Associated with the Prevalence of Periodontal Disease in Korean Adults. Nutrients 2019, 11, 1035. [CrossRef]

3. Cengiz, M.İ.; Zengin, B.; İçen, M.; Köktürk, F. Prevalence of periodontal disease among mine workers of Zonguldak, Kozlu District, Turkey: A cross-sectional study. BMC Public Health 2018, 18, 361. [CrossRef] [PubMed]

4. Sun, H.Y.; Jiang, H.; Du, M.Q.; Wang, X.; Feng, X.P.; Hu, Y.; Lin, H.C.; Wang, B.; Si, Y.; Wang, C.X.; et al. The Prevalence and Associated Factors of Periodontal Disease among 35 to 44 -year-old Chinese Adults in the 4th National Oral Health Survey. Chin. J. Dent. Res. 2018, 21, 241-247. [CrossRef] [PubMed]

5. Figueiredo, A.; Soares, S.; Lopes, H.; Santos, J.N.; Ramalho, L.M.; Cangussu, M.C.; Cury, P.R. Destructive periodontal disease in adult Indians from Northeast Brazil: Cross-sectional study of prevalence and risk indicators. J. Clin. Periodontol. 2013, 40, 1001-1006. [CrossRef] [PubMed]

6. Salih, Y.; Nasr, A.M.; Ahmed, A.B.A.; Sharif, M.E.; Adam, I. Prevalence of and risk factors for periodontal disease among pregnant women in an antenatal care clinic in Khartoum, Sudan. BMC Res. Notes 2020, 13, 147. [CrossRef]

7. García, B.M.; Plana, C.J.M.; González, A.P.I. Prevalence and severity of periodontal disease among Spanish military personnel. BMJ Mil. Health 2020. [CrossRef]

8. Bostanc1, V.; Toker, H.; Senel, S.; Sahin, S. Prevalence of periodontal disease in patients with Familial Mediterranean Fever: A cohort study from central Turkey. Quintessence Int. 2014, 45, 743-748. [CrossRef] [PubMed]

9. Singh, M.; Bains, V.K.; Jhingran, R.; Srivastava, R.; Madan, R.; Maurya, S.C.; Rizvi, I. Prevalence of Periodontal Disease in Type 2 Diabetes Mellitus Patients: A Cross-sectional Study. Contemp Clin. Dent. 2019, 10, 349-357. [CrossRef] [PubMed]

10. Chikte, U.; Pontes, C.C.; Karangwa, I.; Dhansay, K.F.; Erasmus, R.T.; Kengne, A.P.; Matsha, T.E. Periodontal Disease Status among Adults from South Africa-Prevalence and Effect of Smoking. Int. J. Environ. Res. Public Health 2019, 16, 3662. [CrossRef]

11. Nesse, W.; Abbas, F.; Ploeg, I.; Spijkervet, F.K.L.; Dijkstra, P.U.; Vissink, A. Periodontal inflamed surface area: Quantifying inflammatory burden. J. Clin. Periodontol. 2008, 35, 668-673. [CrossRef]

12. Susanto, H.; Nesse, W.; Dijkstra, P.U.; Hoedemaker, E.; van Reenen, Y.H.; Agustina, D.; Vissink, A.; Abbas, F. Periodontal inflamed surface area and C-reactive protein as predictors of HbA1c: A study in Indonesia. Clin. Oral Investig. 2012, 16, 1237-1242. [CrossRef]

13. Orlandi, M.; Graziani, F.; D'Aiuto, F. Periodontal therapy and cardiovascular risk. Periodontol. 2000 2020, 83, 107-124. [CrossRef] [PubMed]

14. Jepsen, S.; Suvan, J.; Deschner, J. The association of periodontal diseases with metabolic syndrome and obesity. Periodontol. 2000 2020, 83, 125-153. [CrossRef]

15. Genco, R.J.; Sanz, M. Clinical and public health implications of periodontal and systemic diseases: An overview. Periodontol. 2000 2020, 83, 7-13. [CrossRef]

16. Sanz, M.; Castillo, M.D.A.; Jepsen, S.; Juanatey, G.J.R.; D'Aiuto, F.; Bouchard, P.; Chapple, I.; Dietrich, T.; Gotsman, I.; Graziani, F.; et al. Periodontitis and cardiovascular diseases: Consensus report. J. Clin. Periodontol. 2020, 47, 268-288. [CrossRef]

17. Bourgeois, D.; Inquimbert, C.; Ottolenghi, L.; Carrouel, F. Periodontal Pathogens as Risk Factors of Cardiovascular Diseases, Diabetes, Rheumatoid Arthritis, Cancer, and Chronic Obstructive Pulmonary Disease-Is There Cause for Consideration? Microorganisms 2019, 7, 424. [CrossRef]

18. Blaschke, K.; Seitz, M.W.; Schubert, I.; Listl., S. Methodological approaches for investigating links between dental and chronic diseases with claims data: A scoping study. J. Public Health Dent. 2019, 79, 334-342. [CrossRef] [PubMed]

19. Sanz, M.; Ceriello, A.; Buysschaert, M.; Chapple, I.; Demmer, R.T.; Graziani, F.; Herrera, D.; Jepsen, S.; Lione, L.; Madianos, P.; et al. Scientific evidence on the links between periodontal diseases and diabetes: Consensus report and guidelines of the joint workshop on periodontal diseases and diabetes by the International Diabetes Federation and the European Federation of Periodontology. J. Clin. Periodontol. 2018, 45, 138-149. [CrossRef] [PubMed]

20. Jin, L.J.; Lamster, I.B.; Greenspan, J.S.; Pitts, N.B.; Scully, C.; Warnakulasuriya, S. Global burden of oral diseases: Emerging concepts, management and interplay with systemic health. Oral Dis. 2016, 22, 609-619. [CrossRef]

21. Nomura, Y.; Morozumi, T.; Nakagawa, T.; Sugaya, T.; Kawanami, M.; Suzuki, F.; Takahashi, K.; Abe, Y.; Sato, S.; Makino-Oi, A.; et al. Site-level progression of periodontal disease during a follow-up period. PLoS ONE 2017, 12, e0188670. [CrossRef] [PubMed] 
22. Morozumi, T.; Nakagawa, T.; Nomura, Y.; Sugaya, T.; Kawanami, M.; Suzuki, F.; Takahashi, K.; Abe, Y.; Sato, S.; Makino-Oi, A.; et al. Salivary pathogen and serum antibody to assess the progression of chronic periodontitis: A 24-mo prospective multicenter cohort study. J. Periodontal Res. 2016, 51, 768-778. [CrossRef]

23. Kakuta, E.; Nomura, Y.; Morozumi, T.; Nakagawa, T.; Nakamura, T.; Noguchi, K.; Yoshimura, A.; Hara, Y.; Fujise, O.; Nishimura, F.; et al. Assessing the progression of chronic periodontitis using subgingival pathogen levels: A 24-month prospective multicenter cohort study. BMC Oral Health 2017, 17, 46. [CrossRef]

24. Krebs, K.A.; Clem, D.S., 3rd. American Academy of Periodontology, Guidelines for the management of patients with periodontal diseases. J. Periodontol. 2006, 77, 1607-1611. [CrossRef]

25. Schöffer, C.; Oliveira, L.M.; Santi, S.S.; Antoniazzi, R.P.; Zanatta, F.B. C-reactive protein levels are associated with periodontitis and periodontal inflamed surface area in adults with end-stage renal disease. J. Periodontol. 2020. [CrossRef]

26. Smojver, B.K.; Altabas, K.; Knotek, M.; Jukić, N.B.; Aurer, A. Periodontal inflamed surface area in patients on haemodialysis and peritoneal dialysis: A Croatian cross-sectional study. BMC Oral Health 2020, 20, 95. [CrossRef]

27. Yamashita, M.; Kobayashi, T.; Ito, S.; Kaneko, C.; Murasawa, A.; Ishikawa, H.; Tabeta, K. The periodontal inflamed surface area is associated with the clinical response to biological disease-modifying antirheumatic drugs in rheumatoid arthritis: A retrospective study. Mod. Rheumatol. 2020, 30, 990-996. [CrossRef] [PubMed]

28. Teke, E.; Kırzıoğlu, E.Y.; Korkmaz, H.; Calapoğlu, M.; Orhan, H. Does metabolic control affect salivary adipokines in type 2 diabetes mellitus? Dent. Med. Probl. 2019, 56, 11-20. [CrossRef] [PubMed]

29. Matsuda, S.; Okanobu, A.; Hatano, S.; Kajiya, M.; Sasaki, S.; Hamamoto, Y.; Iwata, T.; Ouhara, K.; Takeda, K.; Mizuno, N.; et al. Relationship between periodontal inflammation and calcium channel blockers induced gingival overgrowth-a cross-sectional study in a Japanese population. Clin. Oral Investig. 2019, 23, 4099-4105. [CrossRef] [PubMed]

30. Leira, Y.; Yáñez, M.R.; Arias, S.; Dequidt, I.L.; Campos, F.; Sobrino, T.; D’Aiuto, F.; Castillo, J.; Blanco, J. Periodontitis is associated with systemic inflammation and vascular endothelial dysfunction in patients with lacunar infarct. J. Periodontol. 2019, 90, 465-474. [CrossRef] [PubMed]

31. Leira, Y.; Yáñez, M.R.; Arias, S.; Dequidt, I.L.; Campos, F.; Sobrino, T.; D’Aiuto, F.; Castillo, J.; Blanco, J. Periodontitis as a risk indicator and predictor of poor outcome for lacunar infarct. J. Clin. Periodontol. 2019, 46, 20-30. [CrossRef]

32. Iwasaki, M.; Kimura, Y.; Ogawa, H.; Yamaga, T.; Ansai, T.; Wada, W.; Sakamoto, R.; Ishimoto, Y.; Fujisawa, M.; Okumiya, K.; et al. Periodontitis, periodontal inflammation, and mild cognitive impairment: A 5-year cohort study. J. Periodontal Res. 2019, 54, 233-240. [CrossRef] [PubMed]

33. Temelli, B.; Ay, Z.Y.; Aksoy, F.; Büyükbayram, H.İ; Doğuç, D.K.; Uskun, E.; Varol, E. Platelet indices (mean platelet volume and platelet distribution width) have correlations with periodontal inflamed surface area in coronary artery disease patients: A pilot study. J. Periodontol. 2018, 89, 1203-1212. [CrossRef] [PubMed]

34. Epping, L.; Miesbach, W.; Nickles, K.; Eickholz, P. Is gingival bleeding a symptom of type 2 and 3 von Willebrand disease? PLoS ONE 2018, 13, e0191291. [CrossRef] [PubMed]

35. Punj, A.; Santhosh, B.; Shenoy, A.B.; Subramanyam, K. Comparison of endothelial function in healthy patients and patients with chronic periodontitis and myocardial infarction. J. Periodontol. 2017, 88, 1234-1243. [CrossRef]

36. Yoshihara, A.; Sugita, N.; Iwasaki, M.; Wang, Y.; Miyazaki, H.; Yoshie, H.; Nakamura, K. Relationship between renal function and periodontal disease in community-dwelling elderly women with different genotypes. J. Clin. Periodontol. 2017, 44, 484-489. [CrossRef] [PubMed]

37. Yoshihara, A.; Iwasaki, M.; Miyazaki, H.; Nakamura, K. Bidirectional relationship between renal function and periodontal disease in older Japanese women. J. Clin. Periodontol. 2016, 43, 720-726. [CrossRef] [PubMed]

38. Khanuja, P.K.; Narula, S.C.; Rajput, R.; Sharma, R.K.; Tewar, I.S. Association of periodontal disease with glycemic control in patients with type 2 diabetes in Indian population. Front. Med. 2017, 11, 110-119. [CrossRef]

39. Sato, M.; Iwasaki, M.; Yoshihara, A.; Miyazaki, M. Association between periodontitis and medical expenditure in older adults: A 33-month follow-up study. Geriatr. Gerontol. Int. 2016, 16, 856-864. [CrossRef] [PubMed]

40. Jaedicke, K.M.; Bissett, S.M.; Finch, T.; Thornton, J.; Preshaw, P.M. Exploring changes in oral hygiene behaviour in patients with diabetes and periodontal disease: A feasibility study. Int. J. Dent. Hyg. 2019, 17, 55-63. [CrossRef]

41. Weickert, L.; Miesbach, W.; Alesci, S.R.; Eickholz, P.; Nickles, K. Is gingival bleeding a symptom of patients with type 1 von Willebrand disease? A case-control study. J. Clin. Periodontol. 2014, 41, 766-771. [CrossRef]

42. Iwasaki, M.; Taylor, G.W.; Nesse, W.; Vissink, A.; Yoshihara, A.; Miyazaki, H. Periodontal disease and decreased kidney function in Japanese elderly. Am. J. Kidney Dis. 2012, 59, 202-209. [CrossRef] [PubMed]

43. Nesse, W.; Linde, A.; Abbas, F.; Spijkervet, F.K.L.; Dijkstra, P.U.; Brabander, E.C.; Gerstenbluth, I.; Vissink, A. Dose-response relationship between periodontal inflamed surface area and HbA1c in type 2 diabetics. J. Clin. Periodontol. 2009, 36, 295-300. [CrossRef]

44. Tan, A.; Gürbüz, N.; Özbalci, F.İ.; Koşkan, Ö.; Yetkin, A.Z. Increase in serum and salivary neutrophil gelatinase-associated lipocalin levels with increased periodontal inflammation. J. Appl. Oral Sci. 2020, 28, e20200276. [CrossRef]

45. Kasai, S.; Onizuka, S.; Katagiri, S.; Nakamura, T.; Hanatani, T.; Kudo, T.; Sugata, Y.; Ishimatsu, M.; Usui, M.; Nakashima, K. Associations of cytokine levels in gingival crevicular fluid of mobile teeth with clinical improvement after initial periodontal treatment. J. Oral Sci 2020, 62, 189-196. [CrossRef] 
46. Leira, Y.; Ameijeira, P.; Domínguez, C.; Arias, E.L.; Gómez, Á.P.; Mato, M.P.; Sobrino, T.; Campos, F.; D'Aiuto, F.; Leira, R.; et al. Periodontal inflammation is related to increased serum calcitonin gene-related peptide levels in patients with chronic migraine. $J$. Periodontol. 2019, 90, 1088-1095. [CrossRef]

47. Chaparro, A.; Zúñiga, E.; Godoy, M.V.; Albers, D.; Ramírez, V.; Hernández, M.; Kusanovic, J.P.; Gallardo, S.A.; Rice, G.; Illanes, S.E. Periodontitis and placental growth factor in oral fluids are early pregnancy predictors of gestational diabetes mellitus. $J$. Periodontol. 2018, 89, 1052-1060. [CrossRef] [PubMed]

48. Leira, Y.; Lancharro, P.M.; Blanco, J. Periodontal inflamed surface area and periodontal case definition classification. Acta Odontol. Scand 2018, 76, 195-198. [CrossRef]

49. Park, S.Y.; Ahn, S.; Lee, J.T.; Yun, P.Y.; Lee, Y.J.; Lee, J.Y.; Song, Y.W.; Chang, Y.S.; Lee, H.J. Periodontal inflamed surface area as a novel numerical variable describing periodontal conditions. J. Periodontal Implant. Sci. 2017, 47, 328-338. [CrossRef] [PubMed]

50. Sakanaka, A.; Kuboniwa, M.; Hashino, E.; Bamba, T.; Fukusaki, E.; Amano, A. Distinct signatures of dental plaque metabolic by products dictated by periodontal inflammatory status. Sci. Rep. 2017, 7, 42818. [CrossRef]

51. Ramfjord, S.P. Indices for prevalence and incidence of periodontal disease. J. Periodontol. 1959, 30, 51-59. [CrossRef] 